\title{
Trichothecene production in axenic liquid culture of Fusarium graminearum using xylose as a carbon source
}

\author{
Keywords \\ arabinoxylan; Fusarium graminearum; sucrose; \\ trichothecene; xylanase; xylose
}

We examined the effect of using xylose as a carbon source in the medium on trichothecene production by Fusarium graminearum. By frequently adjusting the $\mathrm{pH}$ of the submerged culture in response to the $\mathrm{pH}$ changes of the known trichothecene-inducing sucrose-agmatine culture, trichothecene became detectable from the xylose liquid culture initiated at neutral $\mathrm{pH}$. In contrast to the low $\mathrm{pH}$ requirement of the xylose medium for trichothecene production, the fungus produced the mycotoxin in sucrose liquid culture at neutral $\mathrm{pH}$.

Fusarium graminearum is a causal pathogen of head blight, a devastating disease of wheat and barley ${ }^{1)}$. The fungal species contaminates grains with trichothecene mycotoxins and threatens food safety. The floral cavity between the lemma and palea of the floret is the initial site of infection, where arabinoxylans, the major hemicellulolytic component constituting a flexible matrix with porosity, and cellulose, the cell wall microfibrils embedded in the hemicellulose matrix, are degraded $^{2}$. In the infected tissues, the pathogens produce trichothecenes that function as a virulence factor $^{3)}$. In axenic submerged cultures, it was reported that trichothecene production is effectively induced by sucrose, but not by xylose, when used as a carbon source of the medium ${ }^{4}$. Evolutionary data from wheat xylanase inhibitor genes suggests that arabinoxylan degradation is an important event during infection for the pathogen 51,6$), 7$ ), although the indispensability of xylanase in the infection process is controversial ${ }^{8)}$. Typically, xylose is expected to be the major carbon source that is available at the early stage of infection in wheat flowers, but sucrose is not. Thus, we were interested in seeing whether $F$. graminearum can produce trichothecenes in an axenic culture containing xylose as a carbon source.

We examined whether xylose can be used as a carbon source for trichothecene production in submerged cultures of $F$. graminearum JCM 9873, which accumulates 15 -acetyldeoxynivalenol (15-ADON) in the liquid medium. Decreasing the extracellular $\mathrm{pH}$ of fungal culture during growth is known to promote trichothecene biosynthesis, and as such, a sucrose-agmatine medium (Supplementary Table 1) is often used for trichothecene production $^{9)}$. For this reason, we monitored $\mathrm{pH}$ changes of the sucrose-agmatine culture as a reference for $\mathrm{pH}$ adjustment, and the $\mathrm{pH}$ of fungal cultures to be inspected (cultures with xylose-glutamine, xyloseagmatine, and sucrose-glutamine medium; Supplementary Table 1) was frequently adjusted to that of the reference. Thirty milliliters of each of the above media were inoculated with $1 \%(\mathrm{v} / \mathrm{v})$ of the pre-culture, which was prepared by incubating $50 \mu \mathrm{L}$ of conidial suspension $\left(1 \times 10^{7} / \mathrm{mL}\right)$ in $50 \mathrm{~mL}$ of $Y G$ medium (Supplementary Table 1 ) with reciprocal shaking (125 strokes/min) at $25^{\circ} \mathrm{C}$ for $16 \mathrm{~h}$. The main culture was incubated at 25 ${ }^{\circ} \mathrm{C}$ with gyratory shaking (135 rpm) under two conditions-one with initial $\mathrm{pH}$ adjustment of the medium only and the other with frequent $\mathrm{pH}$ adjustment to the reference trichothecene-inducing culture. The $\mathrm{pH}$ was monitored using a compact $\mathrm{pH}$ meter LAQUAtwin B712 (Horiba Ltd., Kyoto), and adjusted to the reference $\mathrm{pH}$ by adding $0.25 \mathrm{~N}$ or $0.5 \mathrm{~N}$ of $\mathrm{HCl}$ solution (see Supplementary Table 2).

When the xylose-glutamine medium was used without $\mathrm{pH}$ adjustment, the $\mathrm{pH}$ of the fungal culture remained over 6.4 during the incubation period of 120 $h$ (Fig. 1A). No trichothecenes accumulated in the medium, as demonstrated by thin-layer chromatography (TLC) analysis (Fig. 1B; lane 1). With frequent $\mathrm{pH}$ adjustment to that of the continuously decreasing reference culture (Fig. 1A), the same negative result was obtained; 15-ADON production was not observed in the xylose-containing medium with glutamine as a sole nitrogen source (Fig. 1B; lane 2). Similarly, use of xylose did not induce trichothecene production when using agmatine as a sole nitrogen source (Fig. 1B; lane 3), which is in agreement with a previous report ${ }^{10}$. However, when the $\mathrm{pH}$ of the xylose-agmatine culture was frequently adjusted to that of the reference trichothecene-inducing culture (Fig. $1 \mathrm{~A}$ ), the mycotoxin became detectable on a TLC plate after 5 days of incubation (Fig. 1B; lane 4). The result indicates that xylose, with an appropriate nitrogen source such as agmatine, is also used for trichothecene production in the submerged culture if the $\mathrm{pH}$ of the culture is frequently controlled during fungal growth. Compared to the use of the medium containing sucrose with glutamine (Fig.1B; lane 5 and 6), 15-ADON accumulation induced by the xylose-agmatine medium was significantly less (Fig. 1B; lane 3 and 4) despite the presence of agmatine in the medium.

The results obtained in this study demonstrate that F. graminearum produces trichothecenes by using 
(A)

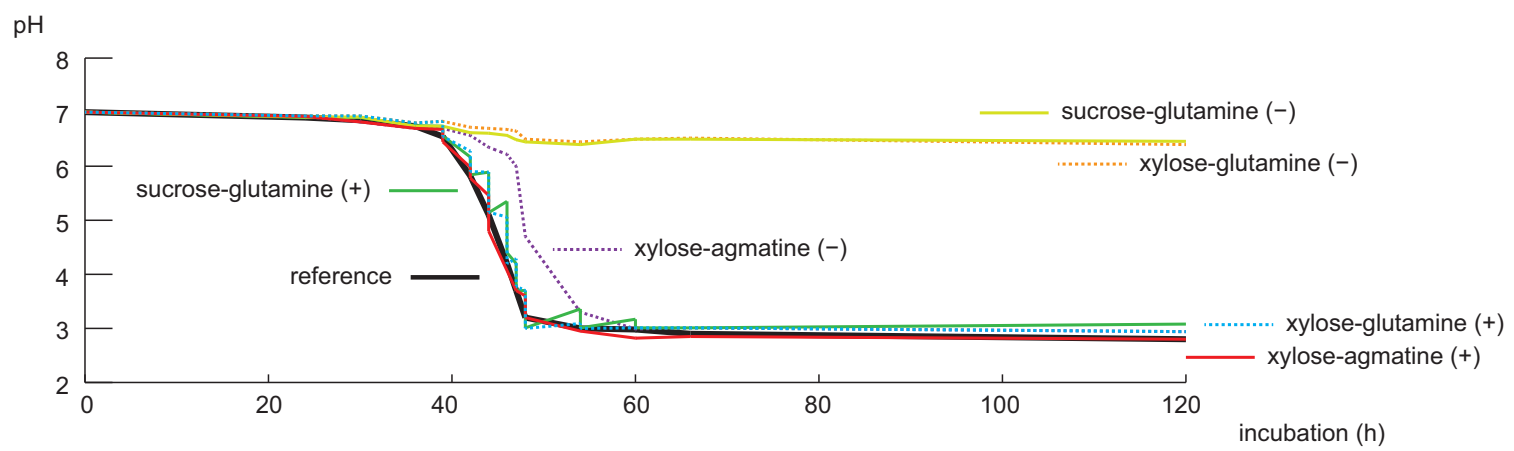

(B)
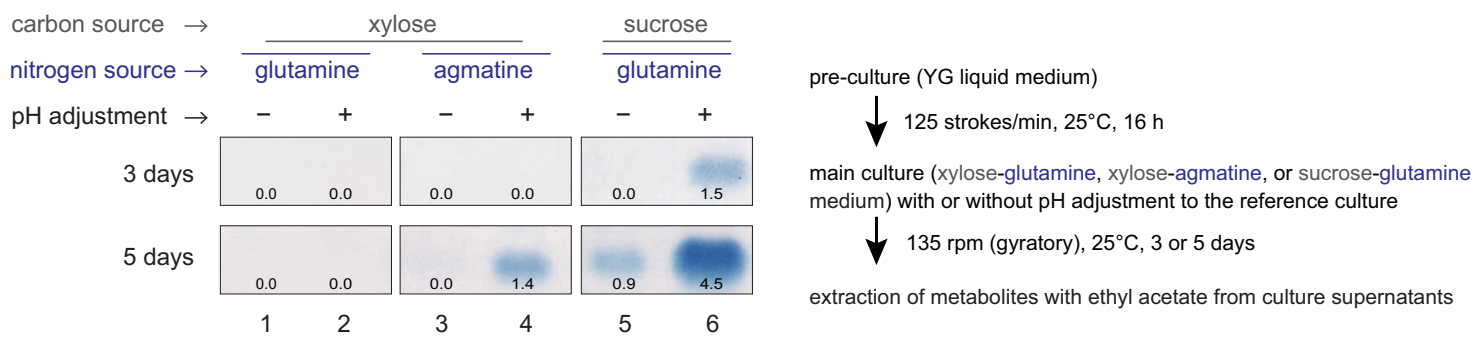

Fig. 1 Relationships between $\mathrm{pH}$ changes and trichothecene production by F. graminearum under different culture conditions.

(A) Time course changes of the culture $\mathrm{pH}$ with (+) or without (-) manual $\mathrm{pH}$ adjustments to that of the known trichothecene-inducing sucroseagmatine culture (reference). For details regarding manipulation of $\mathrm{pH}$ adjustment, refer Supplementary Table 2.

(B) TLC analysis of 15-ADON that accumulated in fungal cultures 3 and 5 days after initiation of the main culture. 15-ADON was extracted from 600 $\mu \mathrm{L}$ of the medium with ethyl acetate and analyzed as described previously ${ }^{11)}$. Toxin amount/mycelial dry weight $(\mu \mathrm{g} / \mathrm{mg})$ is shown on the TLC panel. The experimental scheme is summarized on the right.

xylose as the sole carbon source under certain conditions. At the infection sites of wheat spikelets, growth conditions for the fungus differ significantly from that of the axenic submerged culture ${ }^{10}$. Because aerial hyphae formation generally serves as a stimulus for the fungus to produce trichothecenes ${ }^{11)}$, the quality of carbon sources and $\mathrm{pH}$ are not the sole determinants for the trichothecene productivity in infected spikelets. It may be possible that trichothecene biosynthesis is induced with xylose and other carbon sources available at the site of infected tissues.

Yoshiyuki Kitou ${ }^{1}$, Takahiro Kosaki ${ }^{1+}$, Kazuyuki Maeda ${ }^{1}$, Yoshikazu Tanahashi ${ }^{1}$, Yuichi Nakajima ${ }^{1}$, Kyoko Kanamaru ${ }^{1}$, Tetsuo Kobayashi ${ }^{1}$, Makoto Kimura ${ }^{1}$

${ }^{\dagger}$ Joint first author

${ }^{1}$ Department of Biological Mechanisms and Functions, Graduate School of Bioagricultural Sciences, Nagoya University, Furo-cho, Chikusa-ku, Nagoya, Aichi 464-8601, Japan

\section{Correspondence}

Yoshiyuki Kitou

E-mail: kito.yoshiyuki@a.mbox.nagoya-u.ac.jp

(Received January 07, 2016, Accepted January 15, 2016)

\section{Acknowledgements}

This work was supported by the Programme for Promotion of Basic and Applied Researches for Innovations in Bio-oriented Industry and by a Grant from Noda Institute for Scientific Research.

\section{Supplementary Materials}

Supplementary materials may be found in the online version of this article:

Supplementary Table 1 Media used in this study.

Supplementary Table 2 Time course of $\mathrm{pH}$ changes of the culture and frequent $\mathrm{pH}$ adjustments with $\mathrm{HCl}$. Blue and green letters denote the $\mathrm{pH}$ of the culture before and after $\mathrm{pH}$ adjustment, respectively. The amount of an $\mathrm{HCl}$ solution $(\mu \mathrm{L})$ necessary for the $\mathrm{pH}$ adjustment is shown on a shaded background.

\section{References}

1) Kimura, M., Takahashi-Ando, N., Nishiuchi, T., Ohsato, S., Tokai, T., Ochiai, N., Fujimura, M., Kudo, T., Hamamoto, H., Yamaguchi, I.: Molecular biology and biotechnology for reduction of Fusarium mycotoxin contamination. Pestic Biochem Physiol, 86, 117-123 (2006) 
2) Kang, Z., Buchenauer, $\mathrm{H}$.: Ultrastructural and cytochemical studies on cellulose, xylan and pectin degradation in wheat spikes infected by Fusarium culmorum. J Phytopathol, 148, 263-275 (2000)

3) Kang, Z., Buchenauer, H.: Ultrastructural and immunocytochemical investigation of pathogen development and host responses in resistant and susceptible wheat spikes infected by Fusarium culmorum. Physiol Mol Plant Pathol, 57, 255-268 (2000)

4) Jiao, F., Kawakami, A., Nakajima, T.: Effects of different carbon sources on trichothecene production and Tri gene expression by Fusarium graminearum in liquid culture. FEMS Microbiol Lett, 285, 212-219 (2008)

5) Igawa, T., Ochiai-Fukuda, T., Takahashi-Ando, N., Ohsato, S., Shibata, T., Yamaguchi, I., Kimura, M.: New TAXI-type xylanase inhibitor genes are inducible by pathogens and wounding in hexaploid wheat. Plant Cell Physiol, 45, 1347-1360 (2004)

6) Igawa, T., Tokai, T., Kudo, T., Yamaguchi, I., Kimura, M.: A wheat xylanase inhibitor gene, Xip-I, but not Taxi-I, is significantly induced by biotic and abiotic signals that trigger plant defense. Biosci Biotechnol Biochem, 69, 10581063 (2005)
7) Takahashi-Ando, N., Inaba, M., Ohsato, S., Igawa, T., Usami, R., Kimura, M.: Identification of multiple highly similar XIP-type xylanase inhibitor genes in hexaploid wheat. Biochem Biophys Res Commun, 360, 880-884 (2007)

8) Sella, L., Gazzetti, K., Castiglioni, C., Schäfer, W., D'Ovidio, R., Favaron, F.: The Fusarium graminearum Xyr1 transcription factor regulates xylanase expression but is not essential for fungal virulence. Plant Pathol, DOI:10.1111/ ppa.12456 (2016)

9) Gardiner, D. M., Osborne, S., Kazan, K., Manners, J. M.: Low $\mathrm{pH}$ regulates the production of deoxynivalenol by Fusarium graminearum. Microbiology, 155, 3149-3156 (2009)

10) Kawakami, A., Nakajima, T., Hirayae, K.: Effects of carbon sources and amines on induction of trichothecene production by Fusarium asiaticum in liquid culture. FEMS Microbiol Lett, 352, 204-212 (2014)

11) Ochiai, N., Tokai, T., Takahashi-Ando, N., Fujimura, M., Kimura, M.: Genetically engineered Fusarium as a tool to evaluate the effects of environmental factors on initiation of trichothecene biosynthesis. FEMS Microbiol Lett, 275, 53-61 (2007) 
Supplementary Table 1 Media used in this study.

Synthetic medium for submerged culture ${ }^{1}$

\begin{tabular}{ll}
\hline \multicolumn{1}{c}{ element } & \multicolumn{1}{c}{ concentration } \\
\hline carbon source $^{2}$ & $30 \mathrm{~g} / \mathrm{L}$ \\
$\mathrm{KH}_{2} \mathrm{PO}_{4}$ & $1 \mathrm{~g} / \mathrm{L}$ \\
$\mathrm{KCl}$ & $0.5 \mathrm{~g} / \mathrm{L}$ \\
$\mathrm{MgSO}_{4} \cdot 7 \mathrm{H}_{2} \mathrm{O}$ & $0.5 \mathrm{~g} / \mathrm{L}$ \\
trace elements $^{3}$ & $0.2 \mathrm{~mL} / \mathrm{L}$ \\
$\mathrm{FeSO}_{4} \cdot 7 \mathrm{H}_{2} \mathrm{O}$ & $10 \mathrm{mg} / \mathrm{L}$ \\
nitrogen source & $5 \mathrm{mM}$ \\
\hline
\end{tabular}

$1 \mathrm{pH}$ is adjusted to 7.0 with $\mathrm{NaOH}$.

2 sucrose or xylose.

3 filter-sterilized.

${ }^{4}$ glutamine or agmatine.

$5,000 \times$ Trace elements

\begin{tabular}{ll}
\hline \multicolumn{1}{c}{ element } & \multicolumn{1}{c}{ concentration } \\
\hline citric acid & $5 \mathrm{~g} / 100 \mathrm{~mL}$ \\
$\mathrm{MnSO}_{4}$ & $50 \mathrm{mg} / 100 \mathrm{~mL}$ \\
$\mathrm{ZnSO}_{4} \cdot 6 \mathrm{H} 2 \mathrm{O}$ & $5 \mathrm{~g} / 100 \mathrm{~mL}$ \\
$\mathrm{H}_{3} \mathrm{BO}_{3}$ & $50 \mathrm{mg} / 100 \mathrm{~mL}$ \\
$\mathrm{Na}_{2} \mathrm{MoO}_{4} \cdot 2 \mathrm{H}_{2} \mathrm{O}$ & $50 \mathrm{mg} / 100 \mathrm{~mL}$ \\
$\mathrm{CuSO}_{4} \cdot 5 \mathrm{H}_{2} \mathrm{O}$ & $250 \mathrm{mg} / 100 \mathrm{~mL}$ \\
\hline
\end{tabular}

YG medium (for pre-culture)

\begin{tabular}{lll}
\hline \multicolumn{1}{c}{ element } & concentration \\
\hline yeast extract & $5.0 \mathrm{~g}$ & \\
glucose & $20 \mathrm{~g}$ & \\
\hline
\end{tabular}


Supplementary Table 2 Time course of $\mathrm{pH}$ changes of the culture and frequent $\mathrm{pH}$ adjustments with $\mathrm{HCl}$. Blue and green letters denote the $\mathrm{pH}$ of the culture before and after $\mathrm{pH}$ adjustment, respectively. The amount of an $\mathrm{HCl}$ solution $(\mu \mathrm{L})$ necessary for the $\mathrm{pH}$ adjustment is shown on a shaded background.

Click here to download the Excel spreadsheet 